\title{
Improvement of the weight-and-dimensional control within the environmentally friendly transport system development
}

\author{
Elena Vasilyeva ${ }^{1, *}$ \\ ${ }^{1}$ Moscow State University of Civil Engineering, 129337, 26, Yaroslavskoye Shosse, Moscow, Russia
}

\begin{abstract}
The purpose of the research is to estimate the opportunities to promote the transport systems development by the means of introduction of weight-and-dimensional control and improvement of its methods. The existing methods of weight-and-dimensional control are considered. Advantages and disadvantages of the systems in comparison are revealed. According to the research, such results as the reduction of cases of excesses of admissible mass of freight, collecting additional income for the regional budget, the decrease in the destroying impact on highways, the decrease in the expenses on their repair as well as providing sources for financing of such repair, the decrease in ecological harm from driving of overloaded vehicles, the increase in traffic safety, the reduction of quantity of accidents and life losses caused by driving of the overloaded vehicles are possible. Nevertheless, the analyses of the domestic practice prove that some problems of the organization of weight-and-dimensional control exist. The author offers some measures for the solution of these problems. The results of the research can be used both by the specialists of Ministry of Transport, when drawing up the programmes of the transport system development and during approval of rules and standards of freights transportation, and by the transporters, when planning their activity.
\end{abstract}

\section{Introduction}

The introduction of weight-and-dimensional control is caused by several factors, such as safety, preservation of infrastructure and reduction of emissions of pollutants in the atmosphere, decrease in the destroying influence on the road coverings [1-2], which increase with the growth in weight of heavy-loaded transport exponentially.

Destroying of the road coverings is especially relevant in Russia. Construction of the considerable part of highways in Russia happened in the 1960th, when the design load of 6 tons per an axis was assumed. Newer highways were built according to two standards: GOST 52748-2007 and GOST 32960-2014, assuming other design loads (Table 1) [3-4].

\footnotetext{
* Corresponding author: elena.chibisova metr@mail.ru angela-1309.m@yandex.ru
} 
Table 1. Design load for the highways built in Russia according to different standards

\begin{tabular}{|l|c|}
\hline \multicolumn{1}{|c|}{ Highways } & $\begin{array}{c}\text { Design load, tons per } \\
\text { an axi }\end{array}$ \\
\hline Built in the 1960th & 6 \\
\hline New highways: & \\
\hline 1) GOST 52748-2007: & 11.5 \\
- highways of categories IA, IB, II & 10 \\
- highways of categories III and IV & 6 \\
- highways of category V & 11.5 \\
\hline 2) GOST 32960-2014: & 10 \\
- highways with capital road clothes & \\
- highways with the facilitated road clothes and transitional type & \\
\hline
\end{tabular}

One more problem related to the excess of the transported freight is the negative impact on the environment. The largest share in the structure of automobile emissions in a large city is made by trucks, for example in Moscow it is about $50 \%$ of total harmful emissions. At the same time, trucks' exhausts are 15-20 times more aggressive than cars' exhausts. There is a certain relationship between freight cargo transported and the amount of pollutants, released into the atmosphere (Table 2).

Table 2. Mileage emissions of some pollutants during the movement of trucks

\begin{tabular}{|c|c|c|c|c|c|c|c|}
\hline \multirow{2}{*}{$\begin{array}{c}\text { Freight } \\
\text { transported, } \\
\text { tons }\end{array}$} & Engine type & \multicolumn{7}{|c|}{ Mileage emissions, gr per km } \\
\cline { 2 - 8 } & & $\mathrm{CO}$ & $\mathrm{CH}$ & $\mathrm{NO}_{2}$ & $\mathrm{C}$ & $\mathrm{SO}_{2}$ & $\mathrm{~Pb}$ \\
\hline $0.5-2.0$ & $\mathrm{~B}$ & 22 & 3.4 & 2.6 & 0 & 0.13 & 0.019 \\
\hline $2.0-5.0$ & $\mathrm{~B}$ & 52.6 & 4.7 & 5.1 & 0 & 0.16 & 0.023 \\
\hline & $\mathrm{G}$ & 26.8 & 2.7 & 5.1 & 0 & 0.14 & 0 \\
\hline & $\mathrm{D}$ & 2.8 & 1.1 & 8.2 & 0.5 & 0.96 & 0 \\
\hline $5.0-8.0$ & $\mathrm{~B}$ & 73.2 & 5.5 & 9.2 & 0 & 0.19 & 0.029 \\
\hline & $\mathrm{G}$ & 37.4 & 4.4 & 9.2 & 0 & 0.17 & 0 \\
\hline & $\mathrm{D}$ & 3.2 & 1.3 & 11.4 & 0.8 & 1.03 & 0 \\
\hline $8.0-16.0$ & $\mathrm{~B}$ & 97.8 & 8.2 & 10.0 & 0 & 0.26 & 0.038 \\
\hline & $\mathrm{D}$ & 3.9 & 1.6 & 13.4 & 1.0 & 1.28 & 0 \\
\hline more than 16.0 & $\mathrm{D}$ & 4.5 & 1.8 & 16.4 & 1.1 & 1.47 & 0 \\
\hline
\end{tabular}

The figures in Table 2 are true for the smooth movement and compliance of the standard load capacity. But they can increase many times.

Taking into account the specified design loads, the Government of the Russian Federation claimed the following norms in Resolution No 272 approved on April 15, 2011:

- permissible mass of the vehicle;

- permissible load per a vehicle axis;

- maximum permissible dimensions of vehicles.

A vehicle is considered to be oversized if its width exceeds 2.55 meters (for isothermal bodies exceeds 2.6 meters), height exceeds 4 meters, and length exceeds 12 meters for a trailer and a single car, and if its length exceeds 20 meters for the road train. Besides, a car of smaller length will be considered to be oversized if freight in it overhangs more than 2 meters. As for the weight, the quantity of axes of the vehicle, type of the vehicle (a single car or a road train) and the placement of freight, which is expressed in values of the permissible load per an axis matters (thus the limit for a two-axis single car is 18 tons, the limit for a six-axis road train is 44 tons). If the vehicle does not have specified dimensions and weight, it is necessary to get special permission for its movement on roads. Permission is given by Rosavtodor (when at least a part of the way passes on the roads of the federal importance) or by that executive authority, under whose direct authority the roads lying 
along the way are. If the vehicle together with its freight is higher than 4.5 meters, wider than 5 meters or longer than 35 meters, then it for departure on roads not only permission is necessary, but also coordination of its way with other departments or the development of the special project are required. The vehicle which is heavier than 44 tons should wait still until the assessment of technical condition of all the roads along it way or even strengthening of paving is carried out. The vehicles, exceeding the extreme values of dimensions and weight are allowed to come out to the roads only if they transport indivisible freight. If their freight can be sorted with ease without harm for its quality, it has to be transported sorted, including transportation by several cars [5].

Nevertheless, according to the Department of state policy in the field of road economy of the Ministry of Transport of the Russian Federation, more than one third of all the trucks and road trains violate the Rules of transportation of freight by the motor transport, from them more than $50 \%$ move with violation of weight parameters on the mass of the vehicle and (or) on the load of an axis, thus doing serious harm to the highway (Figure 1). Meanwhile, a journey of 1 truck, weighing 20 tons is equal to a journey of 20,000 cars according to the harm done [6]. According to the specialists of the transport organizations, the estimated damage from the excess of the weight norms within the road network of Russia (about 2.6 trillion rubles) twice exceeds the total size of all the road funds.

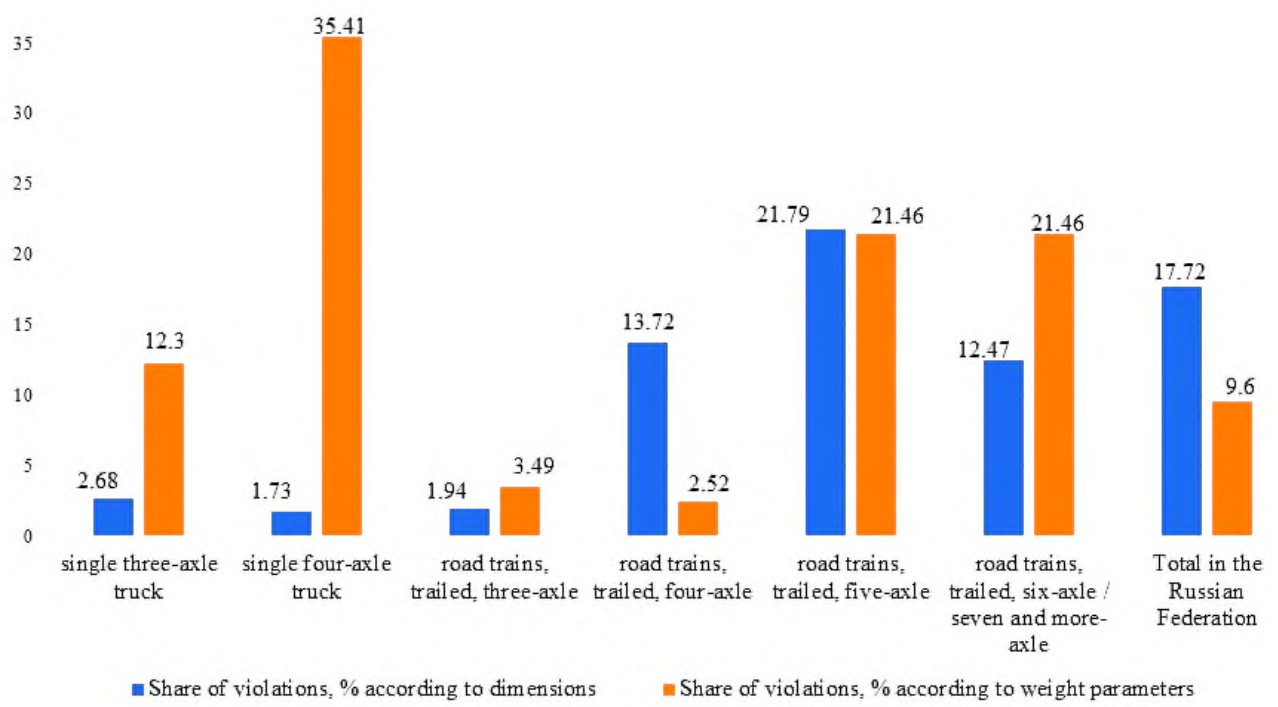

Fig. 1. Share of violations and average overweight for the categories of vehicles in 2018 [7]

Thus, introduction of weight-and-dimensional control systems is very relevant in Russia.

At the same time, the weight-and-dimensional control is a new issue and has no theoretical base. It is possible to note only few works in this area by such experts as: A. Lashkevich (the member of interindustry advisory council at the Ministry of Transport of the Russian Federation), G.A. Volkov (acting as the director of the department of public policy in the field of road economy).

The author of the research considers the existing methods of weight-and-dimensional control, reveals some problems in this area and proposes their possible solutions. 


\section{Methods}

During the research, both general scientific methods (dialectic, formal and logical) and special methods (statistical analysis, comparative analysis, mathematical modeling) were used.

Weight-and-dimensional control can be carried out by traditional methods or can be automated [8].

Initial identification of violators is usually made visually: the traffic police officer to get out the vehicles of the violator from the stream (the car is weighted "up to the boards", it is going more slowly than it could, it has more than five axes, etc.), or with the use of measuring apparatuses (special framework established on the road) [9].

Nowadays there are following methods of weight-and-dimensional control:

1. Weighing on the stationary point.

Structure of the stationary point includes:

- scales by the means of which the axial load of the vehicles is determined during their movement along the roads;

- the special platform for exact weighing;

- stationary / portable scales;

- chamber for the equipment and personnel;

- supervised parking for the vehicles, which has not passed the control;

Stationary point is equipped with the means of communication, regulations of the movement. The special data base is used for collecting, accumulation, processing and data transmission.

2. Mobile posts.

They represent the underlaid axial scales, which are included in the package of the special certified vehicle which makes these posts mobile. Such posts can be arranged on various roads. The platforms, where mobile scales are set, have to be certified, because the precise measurement of the vehicle requires, at least, the flat road [10].

3. Weigh-In-Motion (WIM) systems

The WIM systems use the algorithm of creation of 3-dimensional model and restitution of spatial structure of the object with the use of the modern methods on the basis of the technologies of machine vision, based on high-speed measurement of profiles of the moving vehicles in various sections synchronously with the measurement of the instantaneous speed of the vehicle for each section. [11, 12].

WIM includes: the system of weight control, the system of dimensional control and the system of video surveillance and video fixing.

WIM systems components include:

- Strain gauges - for the determination of weight parameters of the vehicle without reduction in the speed of driving,

- Laser 3D sensors - for the definition of the vehicle dimensions,

- Cameras for photo- and video- fixing - for obtaining images of the vehicle and a discernment of license plates,

- Computing inventory (protected controller) - for the control of the peripheral equipment,

- Communication inventory - for data transmission through $3 \mathrm{G}$, fiber-optic channel or satellite communication, for enciphering of data,

- Inductive sensors - for the definition of the fact of the vehicle driving and the wheel formula and also for the definition of the vehicle speed [13].

4. Weigh-In-Motion with the use of Fiber Optic (WIM FO) systems

WIM includes several sensors in the paving, connected with hardware and the software.

The standard configuration of the WIM system includes 1 or of 2 fiber-optic sensors on per a lane and two inductive loops. Fiber-optic sensors are based on the fiber Bragg lattices and 
allow measuring the pressure created by the passing vehicles as well as the length and width of "print", the wheel position (the position of one or two wheels). WIM FO sensors are installed 2-8 cm below than the top layer of asphalt. They do not demand any power supply network and power supply. Therefore, they are not sensitive to electromagnetic influences.

Nowadays, the automated points of weight-and-dimensional control appear on the federal highways, then they are expected to appear the regional roads.

5. Onboard control systems of weighting

The systems are installed directly on the vehicle, work together with the systems of GLONASS monitoring, and allow carrying out control when loading, unloading and during the vehicles movement.

The considered Weight-and-Dimensional Control systems have their advantages and disadvantages (Table 3).

Table 3. Comparative characteristic of the Weight-and-Dimensional Control systems

\begin{tabular}{|c|c|c|c|}
\hline & $\begin{array}{c}\text { Stationary and mobile } \\
\text { posts }\end{array}$ & $\begin{array}{l}\text { WIM and WIM FO } \\
\text { systems }\end{array}$ & Onboard control system \\
\hline 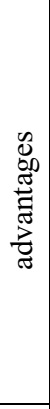 & $\begin{array}{l}\text { - } \quad \text { stop (stop moving) of } \\
\text { the violator's vehicle; } \\
\text { possibility of } \\
\text { calculating of the } \\
\text { damage, actually caused }\end{array}$ & $\begin{array}{l}\text { - } \quad \text { avoiding the human } \\
\text { factor; } \\
\text { working } 365 \text { days a year } \\
\text { in } 24 \times 7 \text { mode and } \\
\text { providing round-the- } \\
\text { clock control; } \\
\text { inevitability of } \\
\text { punishment in case of } \\
\text { violations; } \\
\text { equal control conditions } \\
\text { for all the road users }\end{array}$ & $\begin{array}{l}\text { - avoiding the human } \\
\text { factor; } \\
\text { working } 365 \text { days a year } \\
\text { in } 24 \times 7 \text { mode and } \\
\text { providing round-the- } \\
\text { clock control; } \\
\text { equal control conditions } \\
\text { for all the road users; } \\
\text { opportunity to notice } \\
\text { and to correct violations } \\
\text { by the driver }\end{array}$ \\
\hline 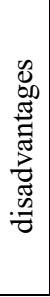 & $\begin{array}{l}\text { insufficient number of } \\
\text { employees to organize } \\
\text { round-the-clock work of } \\
\text { posts; } \\
\text { human factor in the } \\
\text { control; } \\
\text { not } 100 \% \text { vehicle } \\
\text { control coverage }\end{array}$ & $\begin{array}{l}\text { not } 100 \text { th vehicle } \\
\text { control coverage; } \\
\text { the violator's vehicle is } \\
\text { not stopped }\end{array}$ & $\begin{array}{l}\text { - the violator's vehicle is } \\
\text { not stopped }\end{array}$ \\
\hline
\end{tabular}

\section{Results}

According to the results of the statistical analyses, the use of automated systems of weightand-dimensional control allows to decrease the quantity of violations more than 100 times [14].

Besides:

1. The decrease in the quantity of violators allows reducing the damage to highways and saving budgetary funds for repair of public highways.

2. The increase in the receipts of money for the regional budget from the collected penalties for violations of the rules of transportation of freight and indemnification of the harm caused to highways by overloaded vehicles. Besides, payments for the special permissions come to the budget of the region.

3. Ensuring the inevitability of punishment for non-compliance with the special traffic regulation of heavy and large-size vehicles. 
4. The decrease in the quantity of violators (and those are generally the vehicles which driving overloaded) allows increasing the traffic safety considerably.

5. The decrease in the harmful ecological effect.

6. The main social-and-economic effect is saving the human lives.

Nevertheless, some problems, existing in the sphere, were revealed.

The first problem is lack of protection against incorrect work of the system and mistakenly exposed penalties.

The following measures are offered for the solution of this problem:

1) free data providing by the operator of the automated system of weight-and-dimensional control at the request of the transporter;

2) the possibility of carrying out comparative analysis of the same vehicle on different points of the automated system of weight-and-dimensional control in the direction of its travel (Figure 2).

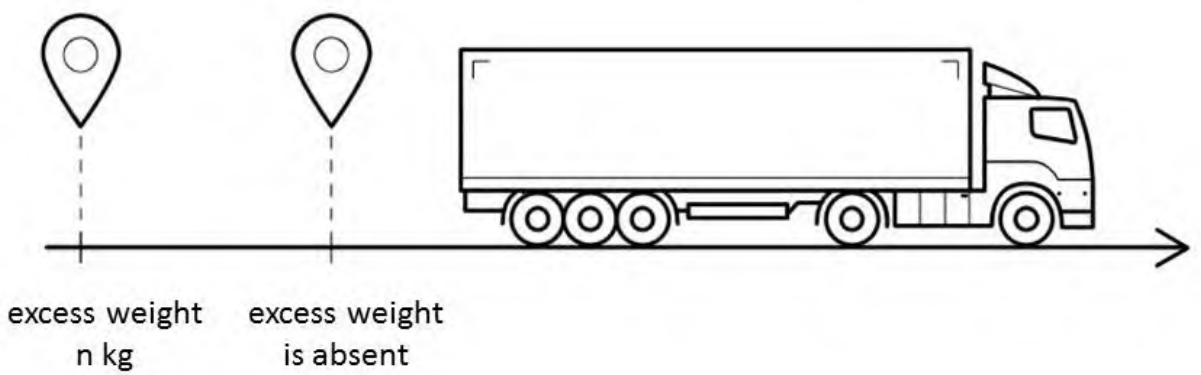

Fig. 2. Comparison of the results on different points of the automated system of weight-anddimensional control in the direction of its travel

The second problem is presented by the penalties, disproportionate to the violation.

The following measures are offered for the solution of this problem:

1) differentiation of penalties taking into account the severity of violations and errors;

2) corrections of penalties set according to the Code of Administrative Offences (Table 3, 4).

Table 4. Corrections of penalties, set according to the Code of Administrative Offences

\begin{tabular}{|c|c|}
\hline $\begin{array}{c}\text { According to the existing Code of } \\
\text { Administrative Offences }\end{array}$ & Corrections \\
\hline $2 \ldots 10 \%$ excess - penalty of & $2 \ldots 10 \%$ excess - penalty of 50,000 rubles \\
$100,000 \ldots 150,000$ rubles & \\
\hline $10 \ldots 20 \%$ excess - penalty of & $10 \ldots 15 \%$ excess - penalty of 75,000 rubles \\
$250,000 \ldots 300,000$ rubles & $15 \ldots 20 \%$ excess - penalty of 100,000 rubles \\
\hline $20 \ldots 50 \%$ excess - penalty of & $20 \ldots 30 \%$ excess - penalty of 200,000 rubles \\
$350,000 \ldots 400,000$ rubles & $30 \ldots 40 \%$ excess - penalty of 300,000 rubles \\
& $40 \ldots 50 \%$ excess - penalty of 400,000 rubles \\
\hline $\begin{array}{c}\text { More than } 50 \% \text { excess - penalty of } \\
400,000 \ldots 500,000 \text { rubles }\end{array}$ & More than $50 \%$ excess - penalty of 500,000 \\
rubles
\end{tabular}

The third problem is absence of the transporter's opportunity to shift the responsibility for the revealed overload to the consignor. 
The solutions are the following:

1) The mechanism of reimposition of the penalty received by the transporter by the means of the automated system of weight-and-dimensional control to the consignor is necessary;

2) Legislative fixing of the possibility of reimposition of the damage to the consignor in case of overload of the vehicle, which arose for the transporter because of the consignor;

3) Introduction of civil responsibility of the consignor to transporter for the distortion of data on weight in the consignment note and for the excess of loading capacity of the vehicle.

\section{Discussion}

Representatives of business (transporter) note that they face additional risks until the following controversial issues of weight-and-dimensional control are handled:

1) additional financial loading (because of obtaining permissions or payment of unfairly high penalties);

2) danger of the sanctions inflicted without any real fault (in case of an error of the automated system. There are precedents of judicial proceedings because of such cases);

3 ) the increase in the quantity of journey, caused by the restriction of legal weight and dimensions of the vehicle.

However, it is necessary to recognize that most controversial matters and disadvantages are peculiar to traditional methods of WIM systems, but they are expected to be solved by the newest WIM FO as well as by the onboard control systems of weighting [15].

\section{Conclusions}

There are sufficient positive effects from the introduction systems of weight-anddimensional control. These systems are constantly developing and improving. At the same time some, such problems exist:

- lack of protection of the participant of transportation against incorrect work of the system and mistakenly exposed penalties;

- penalties that are disproportionate to the violation;

- absence of the transporter's opportunity to shift the responsibility for the overweight to the consignor.

The author offered some solutions of the listed problems. The general approach has to be based on three principles:

- transparency of data;

- comprehensive analysis of the situation;

- fair sanctions.

Then the use of proper weight-and-dimensional control will contribute to the development of modern environmentally friendly transport system. 


\section{References}

1. J. Carson, T. Kearney, Public Roads, 72(6) (2009)

2. D. Labry, V. Dolcemascolo and B. Jacob, Proceedings 8th International Symposium on Heavy Vehicle Weights and Dimensions. Loads, Roads and the Information Highwayí, Johannesburg, South Africa, 8, (2012)

3. A. Mottaeva, E. Vasilyeva, MATEC Web of Conferences, 239, 04019 (2018) doi.org/10.1051/matecconf/201823904019

4. Y. M. Mohammed, N. Uddin, Transportation Management, 1 (2018) doi:10.24294/tm.v1i2.701

5. D. Luskin, C. M. Walton, Effects of truck size and weights on highway infrastructure and operations: a synthesis report (US, TxDOT, 2001) Access mode: http://ctr.utexas.edu/wp-content/uploads/pubs/2122_1.pdf

6. AASHTO, National Academies Report Outlines FHWA Research Path for Revising Truck Size/Weight Limits, AASHTO Journal (2019) [Digital resource]. Access mode: https://aashtojournal.org/2018/11/30/national-academiesreport-outlines-fhwa-research-path-for-revising-truck-size-weight-limits/

7. K. Sekuła, A. Świercz, Key Engineering Materials, 518, 428-436 (2012) DOI: 10.4028/www.scientific.net/KEM.518.428

8. A. Znidaric, J. Kalin, M. Kreslin, P. Kolakowski, Transportation Research Procedia, 14, 4010-4019 (2016) DOI: 10.1016/j.trpro.2016.05.498

9. P, Burnos, D. Rys, Sensors, 17 (9), 2053 (2017)

10. N. Todorovic, M. Subotić, Tehnika-saobraćaj, 61, 661-675 (2014)

11. Zhang Lixin, An evaluation of the Technical and Economic Performance of Weigh-In-Motion Sensing Technology, Master thesis (University of Waterloo, Ontario, Canada, 2007)

12. A. Regan, et al., Strategies for Successful Implementation of Virtual Weigh and Compliance Systems in California (University of California, Berkeley, 2006)

13. B. Jacob, E. O'Brien, S. Jehaes, S. COST 323: Weigh-in-Motion of road vehicles - final report (Paris, 2002)

14. D. Cebon, Handbook of vehicle-road interaction (CRC Press, Taylor \& Francis, 2000)

15. P. Burnos, J. Gajda, R. Sroka, Metrology and Measurement Systems, 24 (4), 743-754 (2018) DOI: $10.24425 / \mathrm{mms} .2018 .124881$ 